\title{
Why Suffering Is Essential to Wisdom
}

\section{Michael S. Brady ${ }^{1}$}

Published online: 14 August 2019

(c) The Author(s) 2019

It is a commonplace to think that suffering is bad and ought to be alleviated. But there are many ways in which suffering can be good-both instrinsically (as an excellence of bodily systems governing damage and repair), and extrinsically (as productive of virtues such as fortitude, patience, compassion, and humility). I want to maintain that suffering has another important role to play: it is essential to wisdom. This idea has precedents. It is, for instance, a tenet of Buddhist thinking, expressed in the legends about Gautama Buddha. These explain the ways in which the experience of suffering is necessary for moral development and enlightenment. The idea is also prominent in Greek thought. Thus Aeschylus writes in the 'Hymn of Zeus' in Agamemnon: "Zeus, who guided men to think, who has laid it down that wisdom comes alone through suffering." 1 And the idea that suffering promotes understanding and wisdom is also central to Nietzsche's thinking. He writes, in typical style: "Whatever has been granted to [the soul] of profundity, secret, mask, spirit, cunning, greatness - was it not granted to it through suffering, through the discipline of great suffering?"2

But why is suffering so essential to wisdom? Two lines of thought seem to be particularly promising here. The first is that suffering is vital for disclosing certain values to us - as Mark Johnston has argued with respect to (dis)values such as "the banal ... the horrific and the plain old ... repellent." Johnston thinks that being affected by such things is necessary for knowledge of them. But suffering also facilitates our understanding of a wide range of negative values, by focusing our attention onto evaluative situations, and motivating the search for reasons that bear on whether things are as they are emotionally presented as being. ${ }^{4}$ For there are very

\footnotetext{
1 Aeschylus I: Oresteia, trans. R. Lattimore, Chicago: The University of Chicago Press (1953), pp. 39-40.

2 Beyond Good and Evil, p. 225.

3 p. 182.

4 See my Emotional Insight: The Epistemic Role of Emotional Experience, Oxford: Oxford University Press (2013).
}

Michael S. Brady

Michael.Brady@glasgow.ac.uk

1 University of Glasgow, Glasgow, Scotland 
close links between emotion and attention; and one of the important things that emotion does, to assist us in our epistemic lives, is to keep attention focused on some initiating object or event until we have a more discriminating picture of our evaluative situation. ${ }^{5}$ This effect is particular prominent in the case of negative emotion, which promotes a 'local' rather than a 'global' attentional focus. ${ }^{6}$ Since attaining a more discriminating view of emotional objects and events is at the heart of understanding them, and since understanding is one of the central components of wisdom, then it is difficult to think that the latter virtue could be attained without the focusing of attention and understanding of value that suffering brings.

A second component of wisdom is a particular kind of reflectiveness. Here too, suffering - in particular, the kind of suffering that occurs as a result of difficult or traumatic life experiences-generates much more in the way of beneficial reflection than positive experiences. The kind of beneficial reflection thought to be at the heart of posttraumatic and stress-related growth is a kind of self-reflection, in which a person tries to understand and make sense of her experiences, and fit them into a broader narrative of her life. Thus Dan McAdams writes: "Negative events produce more cognitive activity in general and more efforts to engage in causal reasoning, compared to positive events. At the level of the life story, negative events seem to demand an explanation. They challenge the storyteller to make narrative sense of the bad thing that happened."7 Further support for this line of thinking comes from recent work by Weststrate and Glück, who argue that reflection, in the form of "exploratory processing of difficult life experience", is a determinant of and positively associated with wisdom. Their hypothesis is that "Through self-reflection, individuals reconstruct, analyze, and interpret real-life sequences of thought, emotion, and action for meaning. The life lessons and insights arrived at through selfreflection lead to an ever-deepening and more complex appreciation of life, which we might call wisdom." 8 The kind of reflection they have in mind here is not that which seeks to understand why objects and events have certain value. Instead, exploratory processing is an "investigative, analytical, and interpretive approach to self-reflection on life events, which emphasizes meaning-making (i.e., extracting lessons and insights), complexity, and growth from the past." 9 Experimental evidence from across three studies confirmed their hypothesis, and it is important to note that the results are related to negative experiences.

Why might reflection on negative rather than positive experiences be correlated with wisdom? One suggestion is that reflecting on the latter might make us realise how fragile such experiences are, or how they came about merely as a result of good fortune-and reflection like this might very well undermine the positive experience

\footnotetext{
${ }^{5}$ For a neuroscientific perspective on this, see Joseph LeDoux, The Emotional Brain, New York: Simon \& Schuster. For a philosophical, see Thomas Reid (1969), Essays on the Active Powers of the Human Mind, B. Brody, B. (ed.), Cambridge, Mass.: MIT Press.

${ }^{6}$ Fredrickson B.L. \& Branigan C. (2005), 'Positive emotions broaden the scope of attention and thought-action repertoires', in Cognition \& Emotion, 19: 313-332;

7 McAdams, D. (2008) 'Personal Narratives and the Life Story', in The Handbook of Personality: Theory and Research (Third Edition), John, O.P., Robins, R.W. and Pervin, L.A. (eds.), New York: Guilford Press, p. 254.

8 p. 802.

${ }^{9}$ p. 809.
} 
entirely. Suppose we meet our beloved by happenstance-bumping into them in a crowded pub. In such cases it could very easily have been the case that we didn't meet them, didn't fall in love, didn't get to enjoy the rest of our lives together. This kind of good fortune - that could very easily have passed us by-isn't something we like to reflect upon. What if I arrived at the pub 10 minutes later? Because of this, we might very well be disinclined to think about the meaning of positive experiences, on pain of their disappearing.

Whatever the ultimate explanation, it seems clear that experiences of suffering are extremely valuable for the development and cultivation of two core elements of wisdom-understanding of value, and self-reflectiveness - such that without them it is doubtful that we could possess the executive virtue that is at the heart of our epistemic and practical lives. Clearly suffering is not sufficient for wisdom; but the above considerations strongly suggest that it is necessary.

Open Access This article is distributed under the terms of the Creative Commons Attribution 4.0 International License (http://creativecommons.org/licenses/by/4.0/), which permits unrestricted use, distribution, and reproduction in any medium, provided you give appropriate credit to the original author(s) and the source, provide a link to the Creative Commons license, and indicate if changes were made.

Publisher's Note Springer Nature remains neutral with regard to jurisdictional claims in published maps and institutional affiliations. 